\title{
Cardiopulmonary exercise testing and its relation to oxidative stress in patients with hypertension
}

\author{
Milica Dekleva ${ }^{1}$, Jelena Suzic Lazic ${ }^{2}$, Milena Pavlovic-Kleut ${ }^{2}$, Sanja Mazic ${ }^{3}$, Angelina Stevanovic ${ }^{4}$, \\ Ivan Soldatovic ${ }^{5}$, Natasa Markovic-Nikolic ${ }^{1}$ and Branko Beleslin ${ }^{6}$
}

An increase in reactive oxygen species has been implicated in the pathologies of hypertension. This study was designed to evaluate antioxidant activity in hypertensive patients and to assess the relationship between oxidative stress and exercise tolerance in hypertensive patients with mild left ventricular diastolic dysfunction (LVDD). A total of 42 patients, aged $51 \pm 9$ years, with a long history of hypertension and mild LVDD (mitral flow velocities-E/A $<1$, deceleration time of $E>220 \mathrm{~ms}$, and preserved ejection fraction-EF $>50 \%$ ), and 30 controls without cardiovascular disease, aged $50 \pm 7$ years, underwent cardiopulmonary exercise testing (CPET). Peak oxygen uptake (peak $\mathrm{VO}_{2}$ ), oxygen pulse $\left(\mathrm{VO}_{2} /\right.$ heart rate (HR)) and ventilatory anaerobic threshold (VAT) were obtained during CPET. Antioxidant activity of superoxide dismutase (SOD) and glutathione peroxidase in the blood was measured before and after exercise. Reduced peak $\mathrm{VO}_{2}(1715 \pm 426$ vs. $\left.2083 \pm 465 \mathrm{ml} \mathrm{min}^{-1}, P<0.001\right), \mathrm{VO}_{2} / \mathrm{HR}(12.0 \pm 2.8 \mathrm{vs}$. $14.6 \pm 3.3 \mathrm{ml}$ per beat, $P<0.001)$ and percentage of peak $\mathrm{VO}_{2}$ at VAT $(55.5 \pm 15.8 \%$ vs. $64.5 \pm 14.7 \%, P=0.007)$ were observed in hypertensive patients, compared with controls. Antioxidant protection was significantly attenuated in hypertensive patients, compared with controls, before $(945 \mathrm{vs} .1006, P=0.012)$ and after exercise (954 vs. 1051, $\boldsymbol{P}<0.001)$. The level of SOD before and after exercise was significantly associated with LVDD in hypertensive patients $(P=0.012$ and 0.02 , respectively). In addition, the degree of LVDD before exercise $(E / A)$ influenced the degree of exercise capability (peak $\left.\mathrm{VO}_{2}\right)(P=0.016)$. Asymptomatic hypertensive patients with mild LVDD had reduced cardiopulmonary capacity, accurately identified by CPET. The redox state in hypertensive patients was significantly related to LVDD and exercise tolerance. Attenuated antioxidant protection was associated with long-term hypertension. Hypertension Research (2012) 35, 1145-1151; doi:10.1038/hr.2012.115; published online 9 August 2012

Keywords: diastolic dysfunction; exercise capacity; hypertension; superoxide dismutase

\section{INTRODUCTION}

Left ventricular diastolic dysfunction (LVDD), which is detected and characterized by Doppler echocardiography, appears early in hypertensive patients, before the onset of abnormal remodeling or left ventricular (LV) hypertrophy, and progressively deteriorates over time. ${ }^{1-4}$ Despite the fact that the initial clinical symptoms predominantly occur during exercise, most studies of hypertensive patients have focused on the parameters of LVDD while at rest. ${ }^{2,5-7}$ Cardiopulmonary exercise testing (CPET) is a recommended technique for the evaluation of the putative mechanism that underlies exercise intolerance in patients with heart failure. ${ }^{8,9}$ In patients with hypertension, impaired LV relaxation and reduced compliance yields inadequate filling at normal diastolic pressures. During exercise, the consequent elevation of left atrial pressure may stimulate receptors associated with augmented ventilation. Elevated pressures are transmitted to the pulmonary vascular system and stimulate breathing. These cardiac-induced alterations in ventilation may result in reduced exercise tolerance and may cause mild to moderate abnormalities in gas exchange. ${ }^{10}$

Exercise enhances the hemodynamic and metabolic response in the body, particularly during acute conditions. An immediate effect of exercise is the multiple-fold increase in oxygen consumption $\left(\mathrm{VO}_{2}\right)$. This peak $\mathrm{VO}_{2}$ boost leads to the production of more free radicals in the plasma and tissues and is followed by a subsequent upregulation of antioxidant defense. ${ }^{11-13}$ Therefore, the enhanced level of antioxidants may contribute to the improvement of oxygen uptake and exercise tolerance. Hypertensive patients in a chronic pro-oxidant state experienced an exacerbation of oxidative stress following exercise, compared with healthy individuals. ${ }^{13-15}$ There are reports of oxidative stress in healthy subjects and diabetics, but there is a

\footnotetext{
${ }^{1}$ Department of Cardiology, University Clinical Hospital Center Zvezdara, School of Medicine, University of Belgrade, Belgrade, Serbia; ${ }^{2}$ Clinical Hospital Center 'Dr Dragisa Misovic-Dedinje', Belgrade, Serbia; ${ }^{3}$ Institute of Medical Physiology, School of Medicine, University of Belgrade, Belgrade, Serbia; ${ }^{2}$ Railway Health Institute, Belgrade, Serbia; ${ }^{5}$ Institute of Medical Statistics and Informatics, School of Medicine, University of Belgrade, Belgrade, Serbia and ${ }^{6}$ Cardiology Clinic, Clinical Center of Serbia, School of Medicine, University of Belgrade, Belgrade, Serbia

Correspondence: Professor M Dekleva, Department of Cardiology, University Clinical Center Zvezdara, School of Medicine, University of Belgrade, Dimitrija Tucovica 161, Belgrade 11000, Serbia.

E-mail: mildek@sbb.rs or dekleva.milica@gmail.com

Received 6 March 2012; revised 7 May 2012; accepted 10 May 2012; published online 9 August 2012
} 
limited information on the relationship between acute exercise and oxidative stress in hypertensive patients. ${ }^{12,13}$ Although there has been significant research into the effects of regular exercise on the modulation of antioxidant protection, there are limited reports about the role of antioxidants in exercise tolerance. ${ }^{13,15}$ The main source of oxidative stress in hypertension is the superoxide anion, which is normally short-lived due to its rapid reduction to hydrogen peroxide by superoxide dismutase (SOD), the major endogenous vascular enzymatic antioxidant. Glutathione peroxidase (GPx) reduces hydrogen peroxide and lipid peroxides to water and lipid alcohols, respectively, and in turn reduces oxidase glutathione to glutathione disulphide. ${ }^{14-16}$

The present study was designed to evaluate antioxidant protection and exercise tolerance by CPET in asymptomatic patients with longstanding hypertension and mild LVDD in comparison with nonhypertensive subjects.

\section{METHODS}

The study population included 42 patients with long-term hypertension (more than 2 years) who fulfilled Doppler echocardiographic criteria for mild LVDD and preserved LV ejection fraction (LVEF). The criteria for Doppler echocardiography selection included an impaired relaxation ratio of early to late filling $(E / A)<1$, a deceleration time of early LV filling $>220 \mathrm{~ms}$, a ratio between mitral and annular early diastolic velocity $(E / e)<12$ and a preserved systolic function, that is, LVEF $>50 \%{ }^{2,18}$ Patients were recruited from a larger group of 332 consecutive patients with hypertension who were referred for echocardiography during a 1-year period (2008).

The control group consisted of 30 non-hypertensive subjects without other cardiovascular disease who were matched by age and gender. Exclusion criteria included age $>65$ years, moderate to severe pulmonary disease, long-standing diabetes mellitus, rhythm disturbances, electrical pacemakers or implantable cardiac defibrillators, congenital or valvular heart disease, dilated or hypertrophic cardiomyopathy, previous bypass surgery and symptoms of heart failure or renal failure. Patients already involved in any type of training and those who were unable to perform the exercise test were also excluded. Prior to testing, all the subjects gave their written informed consent, and the study was approved by the local Ethics Committee.

\section{Two-dimensional, M-mode and tissue Doppler echocardiography}

Doppler echocardiography was performed at rest, prior to exercise testing on the same day, using an Aloka SSD 5000 PHD medical ultrasound system (Aloka Co., Ltd., Tokyo, Japan). The following echo variables were measured or derived: LV dimensions, volumes, LVEF, left atrial dimension and volume, peak transmitral early diastolic $(E)$ velocity, peak transmitral late diastolic velocity (A), E/A ratio, annular myocardial tissue velocity $(e)$ and the E/e ratio. The LV dimension, wall thickness and left atrial dimensions were measured from twodimensionally derived M-mode echocardiograms. Left ventricle volumes and LVEF were measured using a biplane approach. ${ }^{17}$ Peak early and late diastolic transmitral velocities were measured using the pulsed Doppler technique with the sample volume placed at the level of the mitral leaflet tips during diastole in the apical four-chamber view. Myocardial annular tissue velocities were recorded with the pulsed Doppler sample volume positioned within $1 \mathrm{~cm}$ of the septal and lateral insertion sites of the anterior and posterior mitral leaflets, respectively. ${ }^{2}$

\section{Analytical procedures}

Activities of the antioxidant enzymes SOD and GPx were assessed as indicators of oxidative stress. ${ }^{11,13,16}$ Antioxidant activity was estimated from blood samples taken before exercise, and 15-20 min after cessation of exercise, which was the suggested time for the objective antioxidant response in normal subjects from previous studies. ${ }^{13,18,19}$ The activity of SOD and GPx $\left(\mathrm{Ug}^{-1} \mathrm{Hb}^{-1}\right)$ was measured by testing the degree of inhibition of the tetrazolium salt oxidation reaction in a $500-\mathrm{nm}$ sample with a commercially available kit (Ransod kit; Randox Laboratories, Crumlin, UK). Study subjects underwent a minimum of $8 \mathrm{~h}$ fasting prior to the blood test to measure glucose and cholesterol levels, and there was no controlled diet in hypertensive patients or controls. Serum biochemical profiles were measured using an autoanalyzer A mercury sphygmomanometer was used to measure the patient's blood pressure (BP) after $5 \mathrm{~min}$ of rest in a quiet environment, with the patient in the sitting position, following the recommendations of the European Society of Hypertension. ${ }^{20}$

\section{Cardiopulmonary exercise test}

Patients underwent exercise testing of metabolic gas exchange by ergospirometry utilizing Jaeger Oxycon Pro (Jaeger, Wuezburg, The Netherlands), with simultaneous heart rate (HR), BP and 12-lead ECG monitoring. The patients performed a continuous symptom-limited maximal test protocol on a bicycle ergometer with an incremental workload of $25 \mathrm{~W}$ every $3 \mathrm{~min}$, starting at $25 \mathrm{~W}^{21}$ Patients were encouraged to reach maximal or near maximal effort by monitoring the respiratory exchange ratio $(>1.1)$. Continuous measurements of respiratory gas exchange (mouthpiece and nose clip) included peak oxygen uptake (peak $\mathrm{VO}_{2}$ ), as well as oxygen consumption at the ventilatory anaerobic threshold (VAT), performed by the ventilatory equivalent method using the breath-by-breath system. ${ }^{21}$ Peak oxygen uptake per kg of body weight (peak $\mathrm{VO}_{2} / \mathrm{kg}$ ), oxygen pulse (peak $\mathrm{VO}_{2} / \mathrm{HR}$ ), minute ventilation at maximal exercise (peak $\mathrm{VE}$ ), metabolic equivalents and $\mathrm{VE} / \mathrm{VCO}_{2}$ were also obtained.

\section{Statistical analysis}

Data are expressed as the mean \pm s.d. Continuous variables are presented as the mean \pm s.d. Categorical variables are presented as percentages. An independent samples $t$-test was used to determine the difference between two groups for all clinical, echocardiographic, Doppler and CPET parameters. For correlation of parameters, we used correlation coefficients $(r)$ of Pearson's test in symmetric quantitative variables, whereby a bivariate normal distribution was assumed; Spearman's rho testing was reserved for ordinal scaled categories. The response of SOD and GPx in different groups was evaluated by an analysis of variance. The linear regression model was applied for multivariate analysis. SPSS statistical software (version 15.01, Chicago, IL, USA) was used, and a $P$-value of $<0.05$ (two tailed) was considered significant.

\section{RESULTS}

\section{Patient characteristics}

The demographic and clinical characteristics of hypertensive patients and controls are presented in Table 1. There were no significant

\section{Table 1 Patients' characteristics}

\begin{tabular}{|c|c|c|c|}
\hline & $\begin{array}{l}\text { Hypertension } \\
\quad(\mathrm{n}=42)\end{array}$ & $\begin{array}{l}\text { Normotensive } \\
\qquad(\mathrm{n}=31)\end{array}$ & $\mathrm{P}$ \\
\hline Age (years) & $50.76 \pm 8.95$ & $49.84 \pm 6.94$ & 0.170 \\
\hline Number of smokers & $33.3 \%$ & $40.8 \%$ & 0.063 \\
\hline Male & $38.6 \%$ & $35.8 \%$ & 0.210 \\
\hline BMI $\left(\mathrm{kg} \mathrm{m}^{-2}\right)$ & $26.65 \pm 3.57$ & $26.50 \pm 2.43$ & 0.681 \\
\hline Glucose $\left(\mathrm{mmol} \mathrm{I}^{-1}\right)$ & $5.80 \pm 1.88$ & $5.69 \pm 0.76$ & 0.424 \\
\hline Cholesterol $\left(\mathrm{mmol} \mathrm{I}^{-1}\right)$ & $5.69 \pm 1.17$ & $6.01 \pm 1.15$ & 0.090 \\
\hline $\mathrm{HDL}\left(\mathrm{mmol} \mathrm{I}^{-1}\right)$ & $1.11 \pm 0.37$ & $1.16 \pm 0.38$ & 0.540 \\
\hline LDL (mmoll-1) & $3.7 \pm 0.9$ & $3.9 \pm 1.0$ & 0.434 \\
\hline Triglycerides $\left(\mathrm{mmoll}^{-1}\right)$ & $2.91 \pm 0.54$ & $3.1 \pm 0.5$ & 0.144 \\
\hline HR (beats per min) & $74.44 \pm 8.88$ & $75.6 \pm 9.9$ & 0.520 \\
\hline $\mathrm{SBP}(\mathrm{mm} \mathrm{Hg})$ & $142.30 \pm 23.32$ & $136.80 \pm 22.50$ & 0.540 \\
\hline $\mathrm{DBP}(\mathrm{mm} \mathrm{Hg})$ & $90.90 \pm 14.62$ & $82.6 \pm 12.63$ & 0.090 \\
\hline $\mathrm{VO}_{2}\left(\mathrm{ml} \mathrm{min}^{-1}\right)$ & $376.07 \pm 105.59$ & $402.64 \pm 85.97$ & 0.340 \\
\hline $\mathrm{VO}_{2}$ per $\mathrm{kg}\left(\mathrm{ml} \mathrm{kg}^{-1} \mathrm{~min}^{-1}\right)$ & $4.89 \pm 1.41$ & $4.85 \pm 1.16$ & 0.560 \\
\hline $\mathrm{VE}\left(\mathrm{I} \mathrm{min}^{-1}\right)$ & $13.19 \pm 3.2$ & $13.06 \pm 3.54$ & 0.519 \\
\hline
\end{tabular}

Abbreviations: BMI, body mass index; DPB, diastolic blood pressure before exercise; HDL, high-density lipoprotein; HR, heart rate; LDL, low-density lipoprotein; SBP, systolic blood pressure before exercise; $\mathrm{VE}$, minute ventilation; $\mathrm{VO}_{2}$, peak oxygen consumption. 
differences in age, gender, body mass index, glucose and cholesterol level, and number of smokers between study groups. Resting cardiopulmonary parameters were comparable for both groups. Patients were taking the following antihypertensive therapy: angiotensin-converting enzyme inhibitors $29 / 42$ (70\%), beta blockers $21 / 42$ (50\%), diuretics 19/42 (45\%) and calcium antagonists 4/42 (9\%). There was no difference in BP between groups at baseline, which indicates that hypertensive medication was keeping the patients' BP controlled.

\section{Doppler echocardiographic findings}

Echocardiographic characteristics are presented in Table 2. Hypertensive patients had significantly higher relative wall thickness and slightly reduced LV end-diastolic diameter compared with controls.

\section{Cardiopulmonary exercise capacity}

The cardiopulmonary characteristics of subjects from both study groups are presented in Table 3. Maximal HR responses were similar in both groups. BPs were similar at rest $(130 / 90$ vs. $125 / 80 \mathrm{~mm} \mathrm{Hg}$, $P=$ not significant), but a significantly higher systolic BP was reached in the hypertensive group at maximal exercise (196 \pm 25 vs. $186 \pm 21 \mathrm{~mm} \mathrm{Hg}, P=0.057)$. Hypertensive patients reached signi-

Table 2 Echocardiographic characteristics of the study patients

\begin{tabular}{lccr}
\hline & Hypertensive $(\mathrm{n}=42)$ & Normotensive $(\mathrm{n}=31)$ & \multicolumn{1}{c}{$\mathrm{P}$} \\
\hline LVEDD $(\mathrm{mm})$ & $50.7 \pm 5.0$ & $52.9 \pm 5.4$ & 0.085 \\
LVESD $(\mathrm{mm})$ & $33.8 \pm 6.1$ & $35.6 \pm 6.15$ & 0.144 \\
IVS $(\mathrm{mm})$ & $10.8 \pm 1.6$ & $9.4 \pm 1.1$ & $<0.001$ \\
PW (mm) & $10.5 \pm 1.45$ & $9.4 \pm 1.05$ & $<0.001$ \\
EDV/bsa $\left(\mathrm{ml} \mathrm{m}^{-2}\right)$ & $64.1 \pm 12.5$ & $63.25 \pm 11.9$ & 0.423 \\
ESV/bsa $\left(\mathrm{ml} \mathrm{m}^{-2}\right)$ & $30.9 \pm 7.5$ & $31.7 \pm 7.8$ & 0.814 \\
LVEF $(\%)$ & $54.3 \pm 7.3$ & $57.2 \pm 6.3$ & 0.061 \\
LA (mm) & $38.8 \pm 5.3$ & $37.7 \pm 4.3$ & 0.323 \\
IVRT(s) & $108.2 \pm 17.6$ & $103.6 \pm 19.7$ & 0.245 \\
\hline
\end{tabular}

Abbreviations: bsa, body surface area; EDV, end-diastolic volume; ESV, end-systolic volume; IVRT, isovolumic relaxation time; IVS, septum thickness; LA, left atrial dimension; LVEDD, left ventricular end-diastolic dimension; LVEF, left ventricular ejection fraction; LVESD, left ventricular end-systolic volume; PW, posterior wall thickness.

Table 3 Data from cardiopulmonary exercise testing

\begin{tabular}{|c|c|c|c|}
\hline & $\begin{array}{c}\text { Hypertensive } \\
(\mathrm{n}=42)\end{array}$ & $\begin{array}{c}\text { Normotensive } \\
\quad(\mathrm{n}=31)\end{array}$ & $\mathrm{P}$ \\
\hline SBP $\max (\mathrm{mm} \mathrm{Hg})$ & $195.5 \pm 25.4$ & $185.9 \pm 21.0$ & 0.037 \\
\hline DBP $\max (\mathrm{mm} \mathrm{Hg})$ & $98.8 \pm 13.0$ & $96.90 \pm 11.37$ & 0.670 \\
\hline Peak HR (beats per min) & $141.31 \pm 16.78$ & $144.16 \pm 15.35$ & 0.088 \\
\hline DP & $27513 \pm 4514$ & $26721 \pm 3639$ & 0.569 \\
\hline Time to RER (min) & $13.46 \pm 3.37$ & $15.87 \pm 3.94$ & $0.001^{*}$ \\
\hline Peak $\mathrm{VO}_{2}\left(\mathrm{ml} \mathrm{min}^{-1}\right)$ & $1714 \pm 426.14$ & $2082 \pm 465.14$ & 0.001 * \\
\hline $\begin{array}{l}\text { Peak } \mathrm{VO}_{2} \text { per kg } \\
\left(\mathrm{ml} \mathrm{kg}^{-1} \mathrm{~min}^{-1}\right)\end{array}$ & $21.27 \pm 6.49$ & $24.66 \pm 3.89$ & $0.007 *$ \\
\hline$\% \mathrm{VO}_{2}$ at VAT & $55.5 \pm 15.75$ & $64.5 \pm 14.69$ & $0.007 *$ \\
\hline MET & $6.07 \pm 1.85$ & $7.05 \pm 1.11$ & $0.007^{*}$ \\
\hline Peak $\mathrm{VO}_{2} / \mathrm{HR}$ (ml per beat) & $12.05 \pm 2.75$ & $14.57 \pm 3.28$ & $0.001^{*}$ \\
\hline $\mathrm{VE} / \mathrm{VCO}_{2}$ & $34.43 \pm 3.63$ & $33.23 \pm 4.74$ & 0.508 \\
\hline
\end{tabular}

Abbreviations: DBP max, maximal diastolic blood pressure; DP, double product; HR, peak heart rate: MET, metabolic equivalents; Peak $\mathrm{VO}_{2}$, peak oxygen uptake; RER, respiratory exchange

ratio; SBP max, maximal systolic blood pressure; VAT, ventilatory anaerobic threshold; $\mathrm{VO}_{2} / \mathrm{HR}$ oxygen pulse; $\mathrm{VE} / \mathrm{VCO}_{2}$, ventilation carbon dioxide slope.

${ }^{*} P<0.05$. ficantly lower peak $\mathrm{VO}_{2} \quad\left(1714 \pm 426\right.$ vs. $2083 \pm 465 \mathrm{ml} \mathrm{min}^{-1}$, $P=0.001)$, peak $\mathrm{VO}_{2} / \mathrm{HR}(12.0 \pm 2.8$ vs. $14.6 \pm 3.3 \mathrm{ml}$ per beat, $P<0.001)$, metabolic equivalent $(6.1 \pm 1.85$ vs. $7.0 \pm 1.11, P=0.007)$ and percentage of peak $\mathrm{VO}_{2}$ at VAT $(55.5 \pm 15.8 \%$ vs. $64.5 \pm 14.7 \%$, $P=0.007)$ compared with controls (Table 3 ).

\section{Antioxidative protection}

Basal level of antioxidant protection according to SOD values before exercise was lower in patients with long-term hypertension, compared with controls ( $941 \pm 120$ vs. $1006 \pm 163, P=0.096)$. The activity of SOD after exercise was attenuated in hypertensive patients (from $941 \pm 120$ vs. $951 \pm 131, P=$ not significant), suggesting higher oxidative stress. However, SOD significantly increased in controls from $1006 \pm 163$ to $1052 \pm 170, P=0.026$, therefore, SOD activity in non-hypertensive compared with hypertensive subjects after exercise was significantly different $(1052 \pm 170$ vs. 951 $\pm 131, P<0.001)$, demonstrating a higher antioxidant response in controls. The results obtained by measuring GPx were not so explicit, that is, the level before and after exercise in both groups was not significantly different (hypertensives compared with non-hypertensives before exercise $46.38 \pm 12.39$ vs. $40.87 \pm 12.27, P=0.061$; after exercise $49.00 \pm 14.55$ vs. $44.80 \pm 10.87, P=0.149)$. However, differences between levels before and after exercise were significantly higher in non-hypertensive subjects (hypertensives compared with non-hypertensives $-3.4 \pm 10.49$ vs. $3.9 \pm 7.60, P<0.001$ ), suggesting a decreased antioxidant reaction of GPx in hypertensive subjects.

To evaluate the influence of age, smoking status and medication usage on the level of SOD before and after exercise, we used a linear regression model (Tables 4 and 5). Smoking status significantly affected the basal level of SOD only in hypertensive patients and not in controls. Exercise response of SOD activity was not affected by any of these factors. The degree of GPx before and after exercise was not controlled by smoking status, age or medication.

The relationship between exercise capacity, oxidative stress and LV diastolic function in patients with hypertension

There was a significant correlation between exercise capacity as measured by peak $\mathrm{VO}_{2}$, and level of SOD, both before $(P=0.001)$ and after exercise $(P=0.012)$ in hypertensive patients, but not in controls (Figure 1).

Table 4 Multivariable model for level of SOD before exercise

\begin{tabular}{|c|c|c|}
\hline & $B$ & $\mathrm{P}$ \\
\hline \multicolumn{3}{|l|}{ Non $H T$} \\
\hline \multicolumn{3}{|l|}{1} \\
\hline Constant & 1198.185 & 0.000 \\
\hline Age & -3.302 & 0.499 \\
\hline Smoking & 30.531 & 0.649 \\
\hline \multicolumn{3}{|l|}{$H T$} \\
\hline \multicolumn{3}{|l|}{1} \\
\hline Constant & 852.035 & 0.006 \\
\hline Age & 1.832 & 0.698 \\
\hline Smoking & -129.414 & 0.038 \\
\hline ACE inhibitors & -25.599 & 0.706 \\
\hline Beta blockers & -117.061 & 0.072 \\
\hline Diuretics & -8.985 & 0.875 \\
\hline
\end{tabular}

Abbreviations: ACE, angiotensin-converting enzyme; $\mathrm{HT}$, hypertensive patients; non $\mathrm{HT}$, patients without hypertension; SOD, superoxide dismutase. Dependent variable: SOD before exercise. 


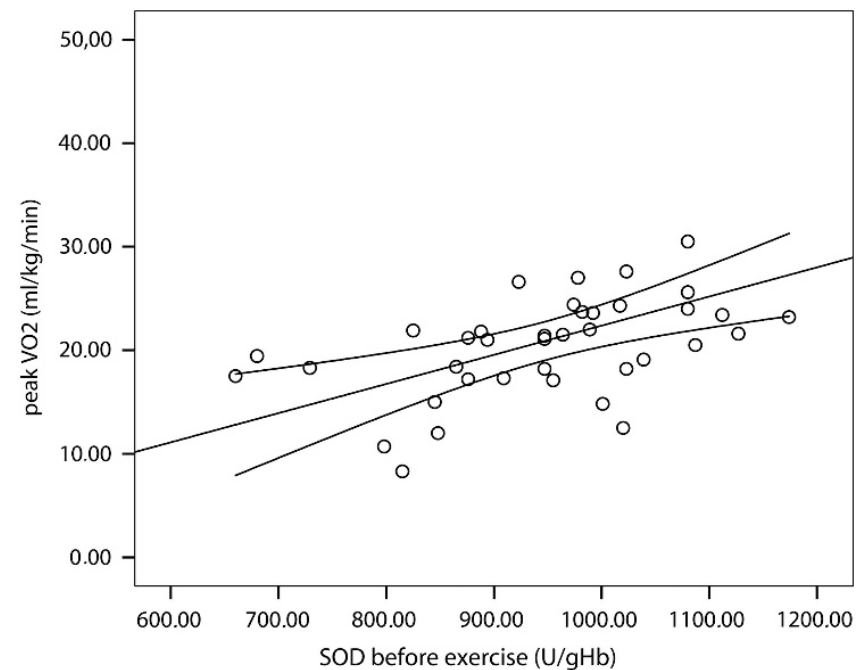

Figure 1 Relationship between antioxidant's level and exercise capacity in hypertensive patients.

Table 5 Multivariable model for level of SOD after exercise

\begin{tabular}{|c|c|c|}
\hline & $B$ & $P$ \\
\hline \multicolumn{3}{|l|}{ Non HT } \\
\hline \multicolumn{3}{|l|}{1} \\
\hline Constant & 884.801 & 0.012 \\
\hline Age & 1.756 & 0.749 \\
\hline Smoking & -115.395 & 0.103 \\
\hline \multicolumn{3}{|l|}{ HT } \\
\hline \multicolumn{3}{|l|}{1} \\
\hline Constant & 1035.260 & 0.000 \\
\hline Age & 1.101 & 0.799 \\
\hline Smoking & 104.232 & 0.089 \\
\hline ACE inhibitors & -51.965 & 0.421 \\
\hline Beta blockers & -102.104 & 0.182 \\
\hline Diuretics & 82.415 & 0.347 \\
\hline
\end{tabular}

Abbreviations: ACE, angiotensin-converting enzyme; $\mathrm{HT}$, hypertensive patients; non $\mathrm{HT}$, patients without hypertension; SOD, superoxide dismutase.

Dependent variable: SOD before exercise.

With regard to the relationship between LVDD and exercise capacity, there was a significant relationship between end-diastolic diameter and volume and peak $\mathrm{VO}_{2}(r=0.433, P<0.001$ and $r=0.513, P<0.001$, respectively), as well as between $E / A$ and peak $\mathrm{VO}_{2}\left(r=0.265, P=0.016\right.$, and peak $\left.\mathrm{VO}_{2} / \mathrm{HR}, r=0.344, P=0.043\right)$.

Furthermore, a significant positive correlation was observed between antioxidant protection (SOD level) and proper LV diastolic filling, as expressed by the $E / A$ ratio $(r=0.434, P=0.005)$ (Figure 2), as well as isovolumic relaxation time $(r=-0.402, P=0.015)$.

From the list of significant correlations, the following parameters of LVDD were entered in a multivariate linear regression model, predicting peak $\mathrm{VO}_{2}$ in patients with hypertension and in nonhypertensive subjects: E/A ratio, SOD level before exercise and enddiastolic diameter. In the hypertensive group, peak $\mathrm{VO}_{2}$ was significantly determined by the level of SOD in addition to factors assessing LV filling $(B=0.030, P=0.002)$ (Table 6).

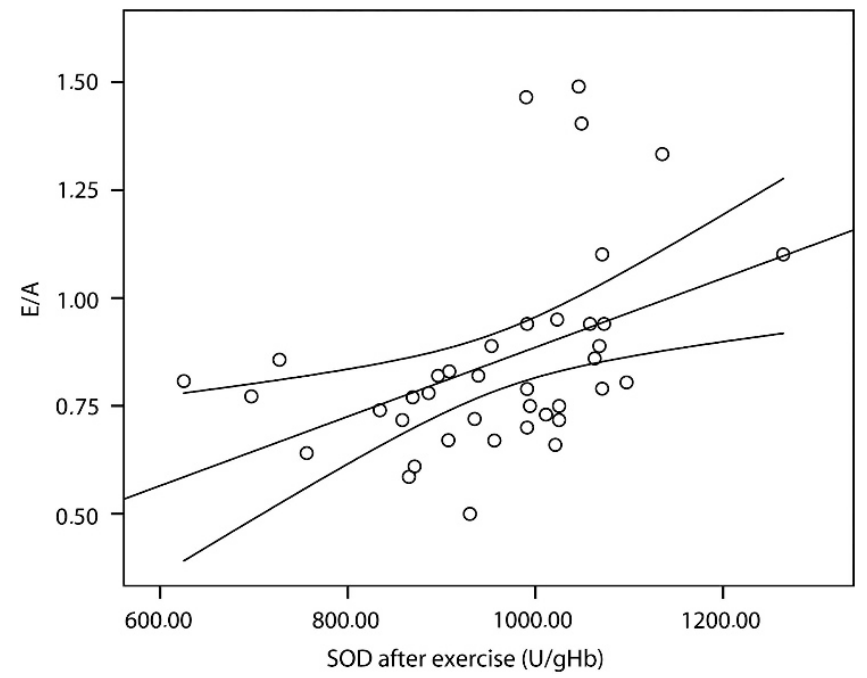

Figure 2 Relationship between antioxidant's level and LV diastolic function. SOD and velocities of LV diastolic filling.

Table 6 Multivariable model for peak $\mathrm{VO}_{2}$

\begin{tabular}{|c|c|c|}
\hline & $B$ & $\mathrm{P}$ \\
\hline \multicolumn{3}{|l|}{ Non $H T$} \\
\hline \multicolumn{3}{|l|}{1} \\
\hline Constant & 17.966 & 0.062 \\
\hline SOD before exercise & -0.002 & 0.631 \\
\hline LVEDD & 0.171 & 0.225 \\
\hline$E / A$ ratio & -0.099 & 0.974 \\
\hline \multicolumn{3}{|l|}{$H T$} \\
\hline \multicolumn{3}{|l|}{1} \\
\hline Constant & -10.842 & 0.461 \\
\hline SOD before exercise & 0.030 & 0.002 \\
\hline LVEDD & 0.073 & 0.719 \\
\hline$E / A$ ratio & -0.323 & 0.941 \\
\hline
\end{tabular}

Abbreviations: $E / A$ ratio, ratio between early and late LV filling; $\mathrm{HT}$, hypertensive patients; LVEDD, left ventricular end-diastolic dimension; non HT, patients without hypertension; SOD, superoxide dismutase.

Dependent Variable: peak $\mathrm{VO}_{2}$.

\section{DISCUSSION}

Asymptomatic patients with long-term hypertension and mild LVDD demonstrated lower functional cardiopulmonary capacity than controls, which can be detected early and recognized using CPET. Depressed functional capacity was associated with lower antioxidant protection as measured by SOD level. Interactive relations between oxidative stress, LVDD and exercise tolerance were observed in these patients.

Mechanisms underlying reduced exercise tolerance in hypertension Recent studies suggest that in patients at rest with isolated LVDD, a combination of systolic and diastolic abnormalities occurs during exercise. $^{22,23}$ In hypertensive patients, mild LVDD at rest was aggravated during exercise, resulting in different modulation of exercise capacity between hypertensive and non-hypertensive subjects. $^{24}$ Our data suggest that hypertensive patients without 
symptoms have significantly reduced functional capacity, for example, lower level of peak $\mathrm{VO}_{2}$ and VAT, compared with controls. Despite the preserved chronotropic responses, patients with long-term hypertension had reduced maximal aerobic power, largely mediated by an impaired increase in stroke volume and limited peak cardiac output. $^{24,25}$ Additionally, the degree of tissue oxygenation and/or capacity for $\mathrm{O}_{2}$ utilization may be responsible for different $\mathrm{O}_{2}$ uptake kinetics in hypertensive and non-hypertensive subjects. ${ }^{26}$

\section{Hypertension and protection against oxidation}

Hypertension is a condition with a permanent shift in redox balance and diminished capacity of the antioxidant defense system. ${ }^{14,15}$ Findings from our study indicate that patients with long-term hypertension have an attenuated SOD level before and after exercise, which is inadequate compared with subjects without hypertension. Low antioxidant bioavailability and decreased content of antioxidant enzymes, including SOD, GPx and catalase, promote cellular oxidative stress and have been implicated in oxidative damage associated with hypertension. ${ }^{14,16,27}$ SOD activity is the first defense against free radical attachment. The $\mathrm{O}_{2}{ }^{-}$produced in the mitochondria during ATP generation by oxidative phosphorylation is immediately converted to hydrogen peroxide by mitochondrial manganese SOD (SOD2) and cytosolic copper-zinc SOD (SOD1). ${ }^{14}$ Small amounts of SOD are extracellular (SOD3), bound to the extracellular matrix and basal membranes and localized between endothelial and vascular muscle. ${ }^{14,27}$ The SOD1 appears to be expressed in all cells, including erythrocytes, such as the predominant isoform. ${ }^{15}$ An important role of cellular SOD in endothelial function is the protection of nitric oxide from oxidative inactivation by superoxide. According to the experimental model, total SOD activity is critically important in protecting the heart from hemodynamic overload. ${ }^{28}$ In addition, the influences of SOD on phagocyte nicotinamide adenine dinucleotide phosphate oxidase and the nitric oxide family of proteins indicate the central role of SOD in redox-mediated signaling in various cardiovascular cells in hypertensive patients. ${ }^{14,16,27,29}$

It is difficult to ascertain higher oxidative stress merely due to an increased response in SOD activity; however, SOD is one of the most important indicators of redox balance in hypertensive patients. The study results vary because SOD enzymatic activation occurs through many different mechanisms and its antioxidant activity is a dynamic process. As with our results, in a study directed by Kasperczyk, erythrocyte concentration and SOD activity were significantly higher in normotensive patients than in hypertensive patients. ${ }^{30}$ Growing evidence suggests that BP modulates measurable oxidant stress-related products, including decreased SOD values. ${ }^{14,16,28}$ On the other hand, a recent study documented higher levels of the biological ROS scavenger SOD in hypertensive subjects compared with normotensive subjects. ${ }^{31}$ Although the reasons have not been fully elucidated, presumably this is a compensatory response to proven high levels of ROS.

Selenium contained in the enzyme GPx catalyzes the removal of hydrogen peroxide through oxidation of reduced glutathione. The dynamic activity of glutathione, including glutathione disulphide, and in turn glutathione oxide, is partially regulated by GPx activity, but other interactions provide many other biochemical pathways. ${ }^{14,16}$ According to our results, the difference in the level of GPx before and after exercise may implicate poorer antioxidant protection in hypertensive patients.

Several factors, such as age, smoking status and the use of some medications, have well-established relationships with oxidative stress and hypertension. ${ }^{32-34}$ We also found a significant influence of smoking status on the SOD level before exercise in hypertensive patients, but not in controls, suggesting that the impairment of antioxidant defense in hypertensive patients was aggravated by cigarette smoking. However, age in both groups did not affect the results.

There are conflicting results from previous studies about the influence of pharmacological treatment on antioxidant status in hypertensive patients. Most studies have shown a decline in oxidative stress as a result of antihypertensive medications, such as angiotensinconverting enzyme inhibitors, angiotensin II receptor antagonists and beta blockers. ${ }^{35-37}$ However, a recent study investigating the role of valsartan on SOD activity demonstrated the profound effect of downregulation of SOD2 in hypertensive patients. ${ }^{31}$ According to our results, there was no significant influence of medication usage on SOD activity in hypertensive patients.

\section{Interactive relations between oxidative stress, LVDD and cardiopulmonary exercise capacity}

An important determinant of exercise capacity in healthy volunteers is the downregulation of the pressure/volume curve in early diastole and the consequent increase in LV distension during exercise. ${ }^{21,38}$ Vanoverschelde et al. ${ }^{38}$ demonstrated that the best predictor of exercise capacity in healthy participants was the ratio of early to late transmitral filling velocities. Arruda et al. ${ }^{10}$ showed that exercise capacity, breathing pattern and gas exchange during exercise are significantly influenced by LV geometry and diastolic function in patients with heart failure and preserved ejection fraction. Altered oxygen uptake and ventilatory efficiency during exercise are related to LV diastolic performance. ${ }^{39}$

The earliest functional changes in hypertension are the prolongation of isovolumic relaxation, reduced rate of rapid filling and increased amplitude of the $A$ wave, most likely caused by an increase in passive diastolic stiffness. Exercise limitation in patients with LVDD is due to a dynamic impairment of $\mathrm{LV}$ active relaxation and compliance $^{5,40}$ Similarly, in our study, mildly impaired LV filling and depressed LV compliance at rest significantly determined exercise tolerance.

Primary ROS generation in response to acute aerobic exercise can occur via several pathways. A single bout of exercise results in the activation of several distinct systems of free radical generation and these may be separated into both primary sources (for example, electron leakage through the mitochondria during aerobic respiration, prostanoid metabolism, catecholamines and the enzymes xanthine oxidase (perhaps via ischemia-reperfusion conditions) and nicotinamide adenine dinucleotide phosphate oxidase), as well as secondary sources (for example, phagocytic cells, disruption of iron-containing proteins and excessive calcium accumulation). ROS production and the subsequent tissue damage resulting from aerobic exercise are largely due to an increased flux in electron transport, leading to an increased leakage of superoxide radicals. ${ }^{13,29}$

It appears that several factors influence both the onset of oxidative stress (for example, intensity and duration of exercise, age, smoking, training status and dietary intake) and the detection of such stress in vivo (for example, biomarker chosen, tissue sampled and timing of sampling). ${ }^{30,31}$ According to previous studies, there is no best point in time for collecting blood samples after aerobic exercise that applies to all markers. ${ }^{13,18}$ Michailidis et al. ${ }^{18}$ showed that the optimum postexercise times for blood collection in untreated individuals are immediately after exercise only for catalase, but not for the other 
antioxidants such as SOD and GPx. All these variables may partially explain some of the inconsistency present in the literature.

The potential role of ROS in impairing exercise performance involves altering contractile function and/or accelerating muscle damage and fatigue as a result of the activity of mitochondrial enzymes. ${ }^{11-14}$ The antioxidant defense system, including SOD, may be reduced temporally in response to the exercise pro-oxidant challenge, but in normal conditions, antioxidant response activates during the recovery period..$^{13}$ In long-term disease, such as hypertension, with the progressive production and accumulation of ROS related to a depletion of enzymatic or non-enzymatic antioxidants, antioxidant response is reduced before and after exercise. ${ }^{16,27,28}$ An attenuated antioxidant defense may implicate a lower percentage of maximal aerobic capacity, specifically, peak oxygen consumption in these patients.

There are reports of upregulation in antioxidant defense and alteration of oxidative stress with regular exercise training. ${ }^{13,19}$ Although many studies are concerned with the effects of regular exercise on the modulation of antioxidant protection, there are fewer studies regarding the role of antioxidants in exercise-tolerance variety. ${ }^{13,18}$ According to our results, in patients with long-term hypertension, full exercise capacity was closely related to antioxidant defense, as measured by SOD activity. Furthermore, the level of SOD before exercise was a significant predictor of peak oxygen uptake in hypertensive patients. Attenuated antioxidant defense in hypertensive patients with mild LVDD may be related to changed energetic reserves, oxygen kinetics and uptake. ${ }^{26}$ Insufficient antioxidant response could be particularly important for understanding the complex and interactive mechanisms underlying the progression from asymptomatic to symptomatic LVDD. ${ }^{3,4}$

\section{Study limitations}

Although we did not perform exercise echocardiography for evaluating actual diastolic dynamics during exercise, we used CPET, which allowed us to assess the contribution of ventilation to functional capacity.

Total antioxidant power or circulating concentrations of antioxidants other than SOD and GPx would provide more insight, but we focused on SOD activity, as it has been shown to have the greatest antioxidant potential in hypertension. Responses in SOD activity may also be due to variations in nitric oxide-mediated $\mathrm{O}_{2}{ }^{-}$scavenging, as nitric oxide is the other direct $\mathrm{O}_{2}{ }^{-}$scavenger; however, properties of our assay allow us to measure only antioxidant enzymatic activity.

In our clinical setting, we were not able to adequately maintain a controlled diet in study subjects, although the potential effects of diet on hypertension and oxidative stress have previously been reported.

\section{Clinical importance}

Detection of functional and antioxidant impairment may be important for the evaluation of asymptomatic hypertensive patients and may control the progression from LVDD to diastolic heart failure. CPET is a reliable, noninvasive and cost-effective technique that ensures accurate assessment of functional impairment in asymptomatic hypertensive patients with isolated LVDD and preserved LVEF. Interrelations between LVDD, cardiopulmonary patterns during exercise and antioxidant protection are applicable to the clinical approach and the medical and exercise prescription. Further studies are required to better understand the role of the redox state in the clinical course of asymptomatic patients with long-term hypertension.

\section{CONFLICT OF INTEREST}

The authors declare no confilct of interest.

\section{ACKNOWLEDGEMENTS}

This work was supported by a project grant from the Serbian Ministry of Science.

1 Ommen SR, Nishimura RA, Appleton CP, Miller FA, Oh JK, Redfield MM, Tajik AJ Clinical utility of Doppler echocardiography and tissue Doppler imaging in estimation of left ventricular filling pressure: a comparative simultaneous Doppler-catheterization study. Circulation 2000; 102: 1788-1794.

2 Nagueh SF, Appleton CP, Gillebert TC, Marino PN, Oh JK, Smiseth OA, Waggoner AD, Flachskampf FA, Pellikka PA, Evangelisa A. Recommendations for the evaluation of left ventricular diastolic function by echocardiography. Eur J Echocardiogr 2009; 10 165-193.

3 Achong N, Wahi S, Marwick TH. Evolution and outcome of diastolic dysfunction. Heart 2009; 95: 813-818.

4 Correa de Sa DD, Hodge DO, Slusser JP, Redfield MM, Simari RD, Burnett JC, Chen $\mathrm{HH}$. Progression of preclinical diastolic dysfunction to the development of symptoms. Heart 2010; 96: 528-532.

5 Zile MR, Baicu CF, Gaasch WH. Diastolic heart failure-abnormalities in active relaxation and passive stiffness of the left ventricle. N Engl J Med 2004; 350: 1953-1959.

6 Hunt SA, Abraham WT, Chin MH, Feldman AM, Francis GS, Ganiats TG, Jessup M Konstam MA, Mancini DM, Michl K, Oates JA, Rahko PS, Silver MA, Stevenson LW, Yancy CW. 2009 focused update incorporated into the ACC/AHA 2005 Guidelines for the Diagnosis and Management of Heart Failure in Adults: a report of the American College of Cardiology Foundation/American Heart Association Task Force on Practice Guidelines: developed in collaboration with the International Society for Heart and Lung Transplantation. Circulation 2009; 119: 391-479.

7 Wang J. Current perspectives on cardiac function in patients with diastolic heart failure. Circulation 2009; 119: 1146-1157.

8 Albouaini K, Egred M, Alahmar A, Wright DJ. Cardiopulmonary exercise testing and its application. Heart 2007; 93: 1285-1292.

9 Arena R, Myers J, Williams MA. Assessment of functional capacity in clinical and research settings. A scientific statement from the American Heart Association Committee on Exercise, Rehabilitation, and Prevention of the Council on Clinica Cardiology and the Council on Cardiovascular Nursing. Circulation 2007; 116: 2-15.

10 Arruda AM, Pellikka PA, Olson TP, Johnson BD. Exercise capacity, breathing pattern, and gas exchange during exercise for patients with isolated diastolic dysfunction. $J \mathrm{Am}$ Soc Echocardiogr 2007; 20: 838-846.

$11 \mathrm{Ji}$ LL. Antioxidants and oxidative stress in exercise. Exp Biol Med 1999; 222 283-292.

12 Leaf DA, Kleinman MT, Hamilton M, Deitrick RW. The exercise induced oxidative stress paradox: the effects of physical exercise training. Am J Med Science 1999; 317 295-300.

13 Fisher-Wellman K, Bloomer RJ. Acute exercise and oxidative stress: a 30 year history Dyn Med 2009; 8: 1186-1195.

14 Paravicini T, Touyz RM. NADPH Oxidases, reactive oxygen species, and hypertension. Diabetes Care 2008; 31: 170-180.

15 Datla SR, Griendling KK. Reactive oxygen species, NADPH oxidases, and Hypertension. Hypertension 2010; 56: 325-330.

16 Parthasarathy S, Khan-Merchant N, Penumetcha M, Santanam N. Oxidative stress in cardiovascular disease. J Nucl Cardiol 2001; 8: 379-389.

17 Schiller NB, Shah PM, Crawford M, DeMaria A, Devereux R, Feigenbaum H, Gutgesell H, Reichek N, Sahn D, Schnittger I. Recommendation for quantification of the left ventricle by two dimensional echocardiography, American Society of Echocardiography Committee on Standards Subcommittee on Quantification of Two Dimensional Echocardiograms. J Am Soc Echocardiogr 1989; 2: 258-267.

18 Michailidis Y, Jamurtas AZ, Nikolaidis MG, Fatouros IG, Koutedakis Y, Papassotiriou I, Kouretas D. Sampling time is crucial for measurement of aerobic exercise-induced oxidative stress. Med Sci Sports Exerc 2007; 39: 1107-1113.

19 Waring WS, Convery A, Mishra V, Shenkin A, Webb DJ, Maxwell SR. Uric acid reduces exrecise-induced oxidative stress in healthy adults. Clin Sci 2003; 105: 425-430.

20 O'Brien E, Asmar R, Beilin L, Imai Y, Mallion JM, Mancia G, Mengden T, Myers M, Padfield P, Palatini P, Parati G, Pickering T, Redon J, Staessen J, Stergiou G, Verdecchia P. European Society of Hypertension recommendations for conventional, ambulatory and home blood pressure measurement. J Hypertens 2003; 21: 821-848.

21 Wasserman K, Hansen JE, Sue DY. Principles of the Exercise Testing and Interpretation. Lippincott Williams \& Wilkins, Baltimore, 1999: 176-190.

22 Tan YT, Wenzelburger F, Lee E, Heatlie G, Leyva F, Patel K, Frenneaux M, Sanderson JE. The pathophysiology of heart failure with normal ejection fraction: exercise echocardiography reveals complex abnormalities of both systolic and diastolic ventricular function involving torsion, untwist, and longitudinal motion. J Am Coll Cardiol 2009; 54: 36-43.

23 Carroll JD, Hess OM, Hirzel HO, Krayenbuehl HP. Dynamics of left ventricular filling at rest and during exercise. Circulation 1983; 68: 59-67. 
24 Kitzman DW, Higginbotham MB, Cobb FR, Sheikh KH. Exercise intolerance in patients with heart failure and preserved left ventricular systolic function: failure of the FrankStarling mechanism. J Am Coll Cardiol 1991; 17: 1066-1072.

25 Fu LH, Ye PX, Sun ZL, Xiang YF, Zhu XZ. Reduced cardiopulmonary exercise capacity in patients with essential hypertension: impact of left ventricular hypertrophy. Zhonghua Xin Xue Guan Bing Za Zhi 2008; 36: 718-721.

26 Kemps HM, Schep G, Zonderland ML, Thijssen EJ, De Vries WR, Wessels B, Doevendans PA, Wijn PF. Are oxygen uptake kinetics in chronic heart failure limited by oxygen delivery or oxygen utilization? Int J Cardiol 2010; 142: 138-144.

27 Watson T, Goon PKY, Lip HYH. Endothelial progenitor cells, endothelial dysfunction inflamation and oxidative stress in hypertension. Antioxid Redox Signal 2008; 10: 1079-1088.

28 Rodrigo R, Prat H, Passalacqua W, Araya J, Guichard C, Bächler JP. Relationship between oxidative stress and essential hypertension. Hypertens Res 2007; 30: 1159.

29 Fisher-Welman K, Bell HK, Bloomer RJ. Oxidative stress and antioxidative defense mechanisms linked to exercise during cardiopulmonary and metabolic disorders. Oxid Med Cell Longev 2009; 2: 43-51.

30 Kasperczyk S, Kasperczyk J, Ostałowska A, Zalejska-Fiolka J, Wielkoszyński T, Swietochowska E, Birkner E. The role of the antioxidant enzymes in erythrocytes in the development of arterial hypertension among humans exposed to lead. Biol Trace Elem Res 2009; 130: 95-106.

31 Yang HY, Kao PF, Chen TH, Tomlinson B, Ko WC, Chan P. Effects of the angiotensin II type 1 receptor antagonist valsartan on the expression of superoxide dismutase in hypertensive patients. J Clin Pharmacol 2007; 47: 397-403.

32 Pannuru P, Vaddi DR, Kindinti RR, Varadacharyulu N. Increased erythrocyte antioxidant status protects against smoking induced hemolysis in moderate smokers. Hum Exp Toxicol 2011; 30: 1475-1481.
33 John JH, Ziebland S, Yudkin P, Roe LS, Neil HA; Oxford Fruit and Vegetable Study Group. Effects of fruit and vegetable consumption on plasma antioxidant concentrations and blood pressure: a randomised controlled trial. Lancet 2002; 359: 1969-1974.

34 Sáez GT, Tormos C, Giner V, Chaves J, Lozano JV, Iradi A, Redón J. Factors related to the impact of antihypertensive treatment in antioxidant activities and oxidative stress by-products in human hypertension. Am J Hypertens 2004; 17: 809-816.

35 Bhuyan BJ, Mugesh G. Antioxidant activity of peptide-based angiotensin converting enzyme inhibitors. Org Biomol Chem 2012; 10: 2237-2247.

36 Dandona P, Karne R, Ghanim H, Hamouda W, Aljada A, Magsino Jr CH. Carvedilol inhibits reactive oxygen species generation by leukocytes and oxidative damage to amino acids. Circulation 2000; 101: 122-124.

37 Flammer AJ, Hermann F, Wiesli P, Schwegler B, Chenevard R, Hürlimann D, Sudano I, Gay S, Neidhart M, Riesen W, Ruschitzka F, Lüscher TF, Noll G, Lehmann R. Effect of losartan, compared with atenolol, on endothelial function and oxidative stress in patients with type 2 diabetes and hypertension. J Hypertens 2007 . 25: 785-791.

38 Vanoverschelde JJ, Essamri B, Vanbutsele R, d'Hondt A, Cosyns JR, Detry JR, Melin JA. Contribution of left ventricular diastolic function to exercise capacity in normal subjects. J Appl Physiol 1993; 74: 225-231.

39 Lam CS, Grewal J, Borlaug BA, Ommen SR, Kane GC, McCully RB, Pellikka PA. Size shape, and stamina: the impact of left ventricular geometry on exercise capacity. Hypertension 2010; 55: 11.

40 Lee AP, Song JK, Yip GW, Zhang Q, Zhu TG, Li C, Chan A, Yu CM. Importance of dynamic dyssynchrony in the occurrence of hypertensive heart failure with normal ejection fraction. Eur Heart J 2010; 31: 2642-2649. 